\title{
Copper-Bronze Catalyst: An Efficient Green Approach for the Synthesis of Dibenzo[b,e][1,4]diazepine Derivatives
}

\author{
ASGHAR JAFAR KHAN ${ }^{1 *}$ and MOHAMMAD A BASEER ${ }^{2}$ \\ ${ }^{1}$ Laboratory of Organic Synthesis, Milliya College, Beed-431122, India \\ ${ }^{2}$ Organic Chemistry Research Laboratory, Yeshwant Mahavidyalaya, Nanded-431602, India \\ khan_asgar@yahoo.com
}

Received 4 August 2014 / Accepted 5 September 2014

\begin{abstract}
Dibenzo[b,e][1,4]diazepine derivatives medicinally important hetero systems have been synthesized by green, efficient and convenient synthesis involving $\mathrm{Cu}$-bronze as a novel catalyst by condensation of $o$-phenylenediamine with aromatic aldehydes. This method is advantageous because of high yield of product easy workup procedure. The synthesized compounds were characterized by ${ }^{1} \mathrm{H}$ NMR, Mass and IR spectral analysis.
\end{abstract}

Keywords: Cu-bronze, Dibenzo[b,e][1,4]diazepine derivatives, $o$-phenylenediamine, substituted aromatic aldehydes.

\section{Introduction}

In the field of organic chemistry, an important largest area of research has been occupied by heterocyclic compounds. Synthesis of $N$ containing heterocyclic compounds especially several type of benzodiazepine derivatives have been provoked much interest due to reported broad spectrum of biological activities such as anti-convulsant, anti-depressive, anti-bacterial, anti-anxiety, anti-inflammatory, tranquilizing, analgesic, hypnotic and sedative agents ${ }^{1,2}$. Benzodiazepines play a leading role in the treatment of cardiovascular disorder $^{3}$. Additionally they have application in fine chemical industries such as photographical dyes for acrylic fiber ${ }^{4}$. Also have been reported to be used as a valuable synthons for the synthesis of fused ring benzodiazepines class of compounds like triazolo, oxadiazolo, oxazino and furanobenzodiazepines ${ }^{5}$. Keeping in view this broad spectrum of biological activity associated with these compounds various synthetic route have been reported in the literature, these include condensation of $o$-phenylenediamine with $\alpha-\beta$ unsaturated carbonyl compounds ${ }^{6}, \beta$-haloketones ${ }^{7}$ or ketones in the presence various catalyst

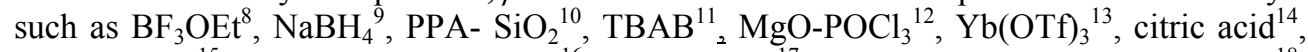
amberlyst- $15^{15}$, sodium dodecyl sulfate ${ }_{2}^{16} \mathrm{Ag}_{3} \mathrm{PW}_{12} \mathrm{O}_{40}{ }^{17}$, solid super acid sulfated zirconia ${ }^{18}$, acetic acid- under $\mathrm{MWI}^{19}, \mathrm{AgNO}_{3}{ }^{20}$, zinc montmorilonite as catalyst at r. ${ }^{21}$, ionic liquid ${ }^{22,23}$, $\mathrm{CAN}^{24}, \mathrm{ZnCl}_{2}{ }^{25}$ and $\mathrm{Hg}(\mathrm{OTf})_{2}{ }^{26}$. However, despite the potential utility of these catalysts, a limitation with the majority of benzodiazepine derivatives syntheses is that of tedious 
workup procedure, formation of side products, involve long reaction time, give low yield of products and use expensive reagents. Further more, very few polycyclic bioactive benzodiazepines are reported in the literature. On the basis of these findings and our continuing research program on the synthesis and search of green catalyst for the synthesis of bioactive interesting heterocycles. ${ }^{11}$ We became interested and designed a green approach for the synthesis of biologically active dibenzo[b,e][1,4]diazepine derivatives. To the best of our knowledge, copper-bronze catalyst for the synthesis of dibenzo diazepine derivatives has not been reported in the literature.<smiles>Nc1ccccc1N</smiles>

$o$-Phenylenediamin

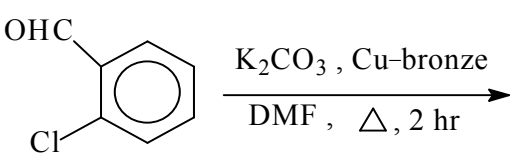

Orthochloro benzaldehyde

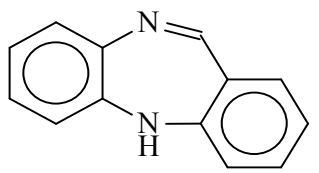

Dibenzo[b,e][1,4]diazepine

Scheme 1. Synthesis of Dibenzo[b,e][1,4]diazepines

The copper-bronze catalyzed condensation and intramolecular cyclization was initially attempted and Buchwald's condition ${ }^{27}$ for intramolecular $N$-arylation reactions were investigated. No reaction was observed without use of catalyst.

\section{Experimental}

All ${ }^{1} \mathrm{H}$ NMR spectra were recorded in $\mathrm{CDCl}_{3}$ on a Brucker AC 200 and Brucker MSL 300 spectrometers and chemical shift were reported in ppm downfield from tetra methyl silane. Infrared spectra were recorded on a Perkin Elmer infra red spectrophotometer using $\mathrm{KBr}$ discs and Mass spectra were taken on ESI-Esquire 3000 Brukers Daltonics instrument, TLC was performed on silica gel coated aluminum plates using ethyl acetate and pet ether $(3: 7 \mathrm{v} / \mathrm{v})$ as eluent, melting points were determined on an electronic melting point apparatus and were uncorrected.

\section{General procedures for the synthesis of Dibenzo[b,e][1,4] diazepine derivatives 3(a-h)}

A mixture of $o$-phenylenediamine (10 mmole), substituted benzaldehydes (10 mmole), Cubronze (10 mol \%) and potassium carbonate (2 equiv), refluxed for $2 \mathrm{~h}$ in $20 \mathrm{~mL}$ dimethyl formamide, the completion of reaction was monitored by TLC. After completion of reaction the reaction mixture was cooled and poured on crushed ice, extracted from ethyl acetate $(20 \mathrm{~mL})$ and washed with water and brine. The solvent was removed by distillation under reduced pressure to afford the products in $80-85 \%$ yield.

\section{Spectral data of the selected products}

3a: IR (KBr): 3389, 2970, 1631,1591,1470,1100,744 $\mathrm{cm}^{-1} ;{ }^{1} \mathrm{HNMR}\left(\mathrm{CDCl}_{3}\right): \delta=3.4$ (brs, 1H), 6.1-7.1 (m, 9H); MS (m/z):194 (M $)$

3b: IR (KBr): 3390, 2950, 1650,1590,1470,1100,744 $\mathrm{cm}^{-1} ;{ }^{1} \mathrm{HNMR}\left(\mathrm{CDCl}_{3}\right): \delta=3.5$ (brs, $1 \mathrm{H}), 6.0-6.9(\mathrm{~m}, 8 \mathrm{H}) ; \quad \mathrm{MS}(\mathrm{m} / \mathrm{z}): 228\left(\mathrm{M}^{+}\right)$

3c: IR (KBr): 3389, 2922, 1600, 1356,746 cm ${ }^{-1} ;{ }^{1} \mathrm{HNMR}\left(\mathrm{CDCl}_{3}\right): \delta=2.5$ (s, 3H) 3.6 (brs, 1H), 6.0-7.5 (m, 8H); $\mathrm{MS}(\mathrm{m} / \mathrm{z}): 208\left(\mathrm{M}^{+}\right)$

3d: IR (KBr): $3377,1664,1599,1440,750 \mathrm{~cm}^{-1} ;{ }^{1} \mathrm{HNMR}\left(\mathrm{CDCl}_{3}\right): \delta=2.2(\mathrm{~s}, 6 \mathrm{H}), 3.4$ (brs, 1H), 6.1-7.3(m, 7H); MS (m/z):222 (M $\mathrm{M}^{+}$.

3h: IR (KBr): 3389, 2970, 1731,1581,1460,1100,744 $\mathrm{cm}^{-1} ;{ }^{1} \mathrm{HNMR}\left(\mathrm{CDCl}_{3}\right): \delta=3.5$ (brs, $1 \mathrm{H}), 6.5-7.0(\mathrm{~m}, 11 \mathrm{H}) ; \mathrm{MS}(\mathrm{m} / \mathrm{z}): 324\left(\mathrm{M}^{+}\right)$ 


\section{Results and Discussion}

In the current strategy, the synthesis of dibenzo[b,e][1,4]diazepine derivatives from $o$-phenylenediamine has been carried out successfully with substituted benzaldehydes in the presence of copper-bronze and potassium carbonate, cleaner transformation obtained, the progress of the reaction was monitored by TLC. The substrate and catalyst is not reported earlier in the literature to the best of our knowledge. The products were obtained in excellent yield, the characterization of the synthesized compounds has been carried out by IR, ${ }^{1} \mathrm{H}-\mathrm{NMR}$ and Mass spectroscopy data ${ }^{28}$ and the results are summarized in Table 1.

Table 1. Cu-bronze catalyzed synthesis of dibenzo[b,e][1,4]diazepine derivatives 3(a-h)

Entry




\section{Conclusion}

We have developed a simple and convenient, environmentally benign, mild synthetic method to afford dibenzo[b,e][1,4]diazepine derivatives with green catalyst under reflux conditions in quantitative yields. To the best of our knowledge, it is probably first example of synthesizing dibenzo[b,e][1,4]diazepine derivatives by using copper-bronze as a catalyst. The simplicity of the method, the ease of the product formation in short reaction time, yield of the product is good.

\section{Acknowledgement}

The authors are thankful to University Grants Commission, New-Delhi for providing financial support to carry out this work. The authors also thankful to the principal, Milliya College, Beed and Principal, Yeshwant College, Nanded, India for providing necessary instrumental facilities.

\section{References}

1. (a) Schutz H, Benzodiazepines; Springer Heidelberg, 1982, 2, 240; (b) Smalley R K, In Comprehensive Organic Chemistry; Barton D and Ollis W D, Eds., Pergamon, Oxford, 1979, 4, 600; (c) Landquist J K, In Comprehensive Heterocyclic Chemistry; Katritzky A R and Rees C W, Eds., Pergamon: Oxford, 1984, 1, 166-170.

2. Randall L O and Kappel B, In Benzodiazepines; Garattini S, Mussini E and Randall L O, Eds., Raven Press: New York, 1973, 27 and references cited therein; (b) Kuo C W, Wang C C, Kaval V and Yao C F, Molecules, 2008, 13(9), 2313-2325; DOI:10.3390/molecules13092313

3. (a) Atwal K S, Begye J L, Hedberg A and Moreland S, J Med Chem., 1987, 30(4), 635-640; DOI:10.1021/jm00387a009 (b) Braccio M D, Grassi G, Roma G, Vergin L, Mura M and Marongiu M E, Eur J Med Chem., 2001, 36(11-12), 935-949; DOI:10.1016/S0223-5234(01)01283-1 (c) Benedikta H, Pudziunaite D, Janciene R and Kosychora L, Arkivoc., 2000, 4, 512.

4. Harris R C and Straley J M, US Patent 1, 537, 753, 757, 1968, Chem Abstr., 1970, 73, $100,054 \mathrm{~W}$.

5. (a) Essaber M, Baouid A, Hasnaoui A, Benharref A and Lavergne J P, Synth Commun., 1998, 28(22), 4097-4104; DOI:10.1080/00397919809458689 (b) ElSayed A M, Abdel,Ghany H and El-Saghier A M M, Synth Commun., 1999, 29(20), 3561-3572; DOI:10.1080/00397919908085990 (c) Xu X J, Wu H T and Jin S, Chin J Chem., 1999, 17(1), 84-91; DOI:10.1002/cjoc.19990170112 (d) Zhang X Y, Xu J X and Jin S, Chin J Chem., 1999, 17(4), 404-410; DOI:10.1002/cjoc.19990170414 (d) Reddy K V V, Rao P S ans Ashok D, Synth Commun., 2000, 30, 1825.

6. Stahlofen P and Ried W, Chem Ber., 1957, 90, 815-824.

7. Ried W and Torinus E, Chem Ber., 1959, 92, 2902.

8. Herbert J A L, Suschitzky H, J Chem Soc Perkin Trans., 1974, 1, 2657-2661; DOI:10.1039/P19740002657

9. Morales H R, Bulbarela A and Contreras R, Heterocycles., 1986, 24, 135.

10. Jung D I, Choi T W, Kim Y Y, Kim I S, Park Y M, Lee Y G and Jung D H, Synth Commun., 1999, 29(11), 1941-1951; DOI:10.1080/00397919908086183

11. Baseer M A and Khan A J, J Chem., 2012, 9(1), 407-417; DOI:10.1155/2012/657439

12. Balakrishna M S and Kaboudin B, Tetrahedron Lett., 2001, 42(6), 1127-1129; DOI:10.1016/S0040-4039(00)02168-7

13. Curini M, Epifano F, Marcotullio M C and Rosati O, Tetrahedron Lett., 2001, 42(18), 3193-3195; DOI:10.1016/S0040-4039(01)00413-0 
14. Baseer M A and Khan A J, Rec Res Sci Tech., 2011, 3, 101-103.

15. Yadav J S, Reddy B V S, Eshwaraian B and Anuradha K, Green Chem., 2002, 4, 592 594; DOI:10.1039/B206558B

16. Sharma G, Kumar R and Chakraborti A K, Tetrahedron Lett., 2008, 49, 4269-4271; DOI:10.1016/j.tetlet.2008.04.146

17. Yadav J S, Reddy B V S, Praveen Kumar S, Nagaiah K, Lingaiah N and Saiprasad P S, Synthesis, 2004, 6, 901.

18. Reddy B M and Sreekanth P M, Tetrahedron Lett., 2003, 44(24), 4447-4449; DOI:10.1016/S0040-4039(03)01034-7

19. Pozarentzi M, Stephanatou J S and Tsoleridis C A, Tetrahedron Lett., 2002, 43(9), 1755-1758; DOI:10.1016/S0040-4039(02)00115-6

20. Kumar R, Chaudhary P, Nimesh S, Varma A K and Chandra R, Green Chem., 2006, 8, 519-521; DOI:10.1039/B601993E

21. Varala R, Ramu E and Adapa S R, Arkivoc, 2006, 171 and references cited therein.

22. Jarikote D V, Siddiqui S A, Rajagopal R, Daniel T, Lahoti R J and Srinivasan K V, Tetrahedron Lett., 2003, 44(1), 183-187; DOI:10.1016/S0040-4039(02)02386-9

23. Yuying Du, Fuli T and Wenzhi Z, Synthetic Commun., 2006, 36(12), 1661-1669; DOI:10.1080/00397910600616602

24. Varala R, Enugala R, Nuvala S and Adapa S R, Synlett., 2006, 1009; DOI:10.1055/s2006-939066

25. Pasha M A and Jayashankara V P, Heterocycles, 2006, 68, 1017-1023.

26. Gourhari M, Utpal K, Rajiv K and Rudraksha N B, Tetrahedron Lett., 2013, 53, 1460-1463; DOI:10.1016/j.tetlet.2012.01.036

27. Review: Yang B H and Buchwald S L, J Organomet Chem., 1999, 576(1-2), 125-146; DOI:10.1016/S0022-328X(98)01054-7 